\title{
Treatment protocol with progesterone, estradiol and oxytocin to improve conception rate and allows for early diagnosis of pregnancy in Black Bengal goat
}

\author{
D Sengupta ${ }^{1 *}$ and S Basu ${ }^{2}$ \\ 1. AICRP on 'Integrated Farming System', Bidhan Chandra Krishi Viswavidyalaya, Mohanpur, Nadia 741252 \\ West Bengal, India; 2. Department of Veterinary Gynaecology and Obstetrics, West Bengal University of \\ Animal and Fishery Science, K. B. Sarani, Kolkata-37, India. \\ * Corresponding author email: dipyamansengupta1@gmail.com \\ Received: 18-09-2011, Accepted: 01-11-2011, Published Online: 01-02-2012 \\ doi: $10.5455 /$ vetworld.2012.269-273
}

\begin{abstract}
This work was performed to develop a treatment protocol that will shorten the length of estrous cycle in mated goats those fail to conceive, without reduction in conception rate. In experiment 1 , ninety goats (single parity, $1 \frac{1}{2}$ to 2 years age) were divided into nine groups of ten goats each. On return to heat, all groups were mated barring groups 1, 3 and 4. On days 3-5 of estrous, progesterone was treated at the dose rate of $10 \mathrm{mg} \mathrm{i.m} \mathrm{(groups} \mathrm{3,} 5$ and 7) or $30 \mathrm{mg}$ i.m. (groups 4, 6 and 8). Groups 7, 8 and 9 received estradiol (500 $\mu$ g i.m.; day 8) + oxytocin (10 IU i.m.; day 9) treatment. Following treatments, the goats were observed for heat and appearance of embryonic vescicles (EV) by transabdominal ultrasonography. In experiment 2 , group $2(n=50)$ was equal to group 8 of experiment 1 and group $1(n=50)$ served as control. The litter size and weight was recorded at birth. Early progesterone treatment significantly $(\mathrm{P}<0.05)$ shortened the cycle length in groups 3 (day 15) and 4 (day 17) respectively compared to control (group 1;21 days), whereas mated group 5 and 6 did not have any difference in conception rate compared to control (group 2). In does of group $5 \& 6$, EVs were observed much earlier than group 2 . Estradiol + oxytocin treatment had no effect on conception rate of group 8, while does of group 7 and 9 returned to heat on day 12 . In experiment 2 , significant difference in conception rate and percentage of single, double, triplet and quadruplet born was observed between control and treated groups while the mean litter weight born was non-significant. Thus early pregnancy diagnosis can be done at by progesterone + estrogen treatment that not only shortens the length of estrous cycle, if the animals fail to conceive, but also improves the conception rate.

Key words: progesterone, estrogen, oxytocin, estrous cycle length, pregnancy, Black Bengal goats
\end{abstract}

To cite this article : Sengupta D and Basu S (2012) Treatment protocol with progesterone, estradiol and oxytocin to improve conception rate and allows for early diagnosis of pregnancy in Black Bengal goat, Vet. World. 5(5): 269-273, doi: 10.5455/vetworld.2012.269-273

\section{I ntroduction}

Estrous cycle in cattle and goats is 21 days in length. If the animal fails to conceive it returns to heat on day 21. Thus non-return to heat on day 21 is an important indicator of pregnancy but such a long period of estrous puts heavy economic burden on the farmers as the maintenance cost of the animals during this period is wasted if they fail to conceive. Moreover, this greatly reduces the productive life of the animals. Thus any method that not only shortens the estrous length but also improves the conception rate will greatly benefit the farmers.

Early progesterone administration has been found to hasten conceptus growth and maturation (Mann et al., 2006). Estrogen administered after day 8 initiates pre-mature luteolysis by up-regulation of endometrial oxytocin receptors (Beard and Lamming,
1994) leading to release of endometrial $\mathrm{PGF}_{2 \alpha}$ Conceptus is able to abrogate the effect of estrogen by the release of interferon tau that down-regulates endometrial estrogen receptors (Spencer and Bazer, 1996). We have therefore attempted to design a treatment protocol using progesterone and estrogen enabling an early pregnancy diagnosis and shortening of estrous length if the animals fail to conceive.

\section{Materials and Methods}

These experiments were conducted in accordance with the Guidelines laid down by EU Directive 2010/63/EU for animal experiments."

Experiment 1: Early Pregnancy Diagnosis:

Regular cycling Black Bengal does $(n=90)$ with body weight of $15-18 \mathrm{~kg}$ (single parity, $1 \frac{1}{2}$ to 2 years age) were selected from different villages of Amdanga 
Block, district 24 Parganas (N), W. Bengal and divided into then groups. The does were selected such that they had their previous heat within last two weeks.

These does were reared by the farmers on their households and maintained by teathering for eight hours. A balanced concentrate mixture of 200 gms per animal per day was provided for approximately 7 days prior to the start of the experiment. The does were dewormed by $150 \mathrm{mg}$ Albendazole (Albomar, Glaxo India Ltd.) before the start of the experiment. The experiment was conducted during the month of September-October 2010.

The goats were brought to heat by two injections of $10 \mathrm{mg} \mathrm{PGF}$ PG $_{2 \alpha}$ Lutalase, Novartis India Ltd.) i.m. 11 days apart and then divided into one of the following groups tabulated as under. Each group was either mated or non-mated (table 1), treated with either/and progesterone (Proluton Depot, Cadila Zydus, India), estrogen (Progynon Depot, Cadila Zydus, India) or oxytocin (Syntocinon, Novartis Pharma Ltd., India).

Table 1. Treatment protocol to different groups of mated and non-mated Black Bengal goats in experiment 1.

\begin{tabular}{|c|c|c|c|c|c|}
\hline Group & $\bar{n}$ & Animals & $\begin{array}{l}\text { Treatm } \\
\text { Progesterone } \\
\text { (day 3-5)* }\end{array}$ & $\begin{array}{l}\text { ment } \\
\text { Estrogen } \\
\text { (day 8) }\end{array}$ & $\begin{array}{l}\text { Oxytocin } \\
\text { (day 9) }\end{array}$ \\
\hline$\overline{1}$ & 10 & non-mated & - & - & --- \\
\hline 2 & 10 & mated & - & - & --- \\
\hline 3 & 10 & non-mated & 10 mg i.m. & - & --- \\
\hline 4 & 10 & non-mated & 30 mg i.m. & - & --- \\
\hline 5 & 10 & mated & 10 mg i.m. & - & --- \\
\hline 6 & 10 & mated & $30 \mathrm{mg}$ i.m. & - & --- \\
\hline 7 & 10 & mated & 10 mg i.m. & $500 \mu \mathrm{g}$ & 10 i.u \\
\hline 8 & 10 & mated & 30 mg i.m. & $500 \mu \mathrm{g}$ & $10 \mathrm{i} . \mathrm{u}$ \\
\hline 9 & 10 & mated & & $500 \mu \mathrm{g}$ & 10 i.u \\
\hline
\end{tabular}

Following treatments the day of returning to heat (DRH) was observed by a vasectomized buck. The day of first appearance of embryonic vescicles (DEV) was recorded by trans-abdominal (5 MHz sector scan) Bmode real time ultrasonography (Mindray, Senzhen, China). The data was analysed by Duncan's test.

\section{Experiment 2: Kidding Rate}

Hundred does having recent kidding during the month of September-October were selected from different villages of Amdanga Block, district 24 Parganas (N), W. Bengal and divided into two groups of fifty does each. They were dewormed by $150 \mathrm{mg}$ Albendazole (Albidol, Concept, India) and received $10 \mathrm{~g}$ vitamin mineral supplementation (Supplevit M, Sarabhai Zydus India) daily for 15 days. On return to post-partam heat the farmers served (hand-mating) their doe to a buck maintained in the same village. Group 1 received no treatment and served as control whereas Group 2 received the same treatment as group
8 of experiment 1.

Goats were observed for non-return to heat on day 21 and these goats were considered pregnant. They were also observed for abortions if any during the gestation period. After kidding, the number of kids born and mean litter weight ( $\mathrm{mlwb}$ ) per doe for the two groups were recorded and data compared by t-test or chi-square test.

\section{Results}

The results indicate that early progesterone $(\mathrm{P})$ exposure significantly $(\mathrm{P}<0.05)$ shortened the length of estrous cycle in does (group $3 \&$ group 4 ) compared to the control group (table 1). However, does exposed to $30 \mathrm{mg} \mathrm{P}$ (group 4) had significantly shortened estrous cycle length compared to $10 \mathrm{mg} \mathrm{P}$ treated group. Early progesterone exposure to mated groups (group 5 \& 6) did not result in shortened estrous cycle length (table 1). There was no significant difference in conception rate between progesterone treated $(70 \%$ in group 5 and $80 \%$ in group 6 ) and control group ( $80 \%$ in group 2).

In early progesterone treated group embryonic vescicles were observed much earlier than the control group (table 2) and the difference was significant $(\mathrm{P}<$ 0.05 ). In does treated with $30 \mathrm{mg}$ progesterone (group 6) embryonic vescicles appeared as early as day 12 (figure-1), thus enabling very early pregnancy diagnosis by ultrasonography. However, embryonic vescicles appeared on day 16 to does treated with 10 $\mathrm{mg}$ progesterone (group 7) and the difference was significant $(\mathrm{P}<0.01)$ from group 6 (day 12). Administration of $500 \mu \mathrm{g}$ estradiol on day 8 of estrous did not affect the conception rate of does treated with

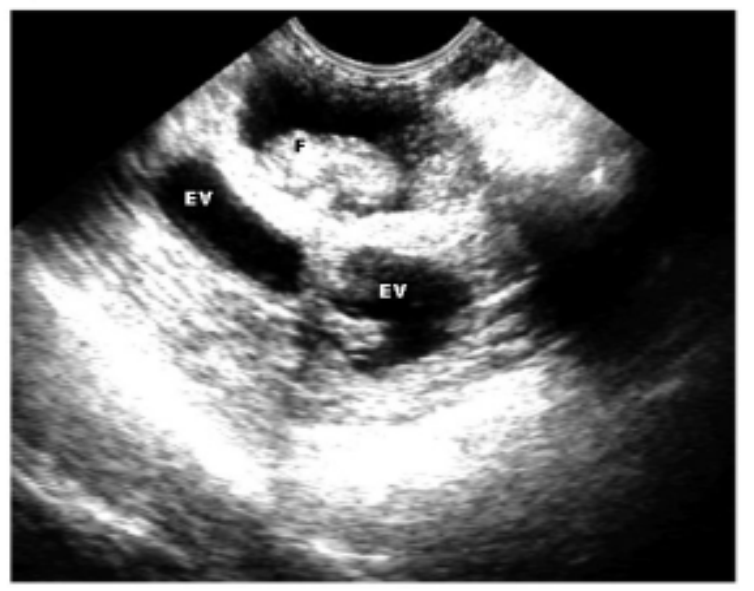

Figure 1. Embryonic vescicles of early pregnancy (day 21) in early progesterone treated goats viewed by $5 \mathrm{MHz}$ transabdominal probe. ( $E V=$ embryonic vescicles, $F=$ fetus) 




Figure 2. Percentage of does with single, twin, triplet and quadruplet births in control $(n=30)$ and treated groups $(n=30)$ of experiment 2 .

$30 \mathrm{mg}$ progesterone (group 8); however does receiving $10 \mathrm{mg}$ progesterone (group 7) and the control group (group 9) returned to heat by day 12 (table 2).

In experiment 2 there was significant difference $(\mathrm{P}<0.05)$ in conception rates between early $\mathrm{P}$ treated $(80 \%)$ and control group $(60 \%)$. The number of kids born from early $\mathrm{P}$ treated $(\mathrm{n}=30)$ and control group $(n=30)$ was 76 and 49 respectively, the difference being highly significant $(\mathrm{P}<0.05)$. The percent of does with single, double, triplet and quadruplet births was significantly $(\mathrm{P}<0.05)$ different between progesterone treated and control groups (figure 2).

Table-2. Day of returning to heat (DRH), appearance of embryonic vescicles (DEV), number not returning to heat on day 21 ( NRH21) for different group of does in experiment 1 .

\begin{tabular}{clllcl}
\hline Group & $\mathbf{n}$ & Animals & DRH & NRH21 & DEV \\
\hline 1 & 10 & non-mated & $20.7^{\mathrm{c}}$ & & \\
2 & 10 & mated & NR21 & 8 & $20.3^{\mathrm{c}}$ \\
3 & 10 & non-mated & $17^{\mathrm{b}}$ & & \\
4 & 10 & non-mated & $15.1^{\mathrm{a}}$ & & \\
5 & 10 & mated & $\mathrm{NR} 21$ & 7 & $16.1^{\mathrm{b}}$ \\
6 & 10 & mated & $\mathrm{NR} 21$ & 8 & $12.6^{\mathrm{a}}$ \\
7 & 10 & mated & 11.75 & $1^{*}$ & \\
8 & 10 & mated & $\mathrm{NR} 21$ & 6 & $12^{\mathrm{a}}$ \\
9 & 10 & mated & 11.90 & & \\
\hline
\end{tabular}

$a, b, c$ : similar alphabets along columns denote homogenous $(P>0.05)$ means * : early embryonic death

The mean litter weight born differed significantly $(\mathrm{P}<0.05)$ between control and treated groups (figure 3 ) for single kidding, but for double, triplet and quadruplet kidding, the difference was non significant. The mean litter weight born for single, double and triplet births in control group (figure 3) were $0.87 \pm 0.04 \mathrm{~kg}(\mathrm{n}=8)$,

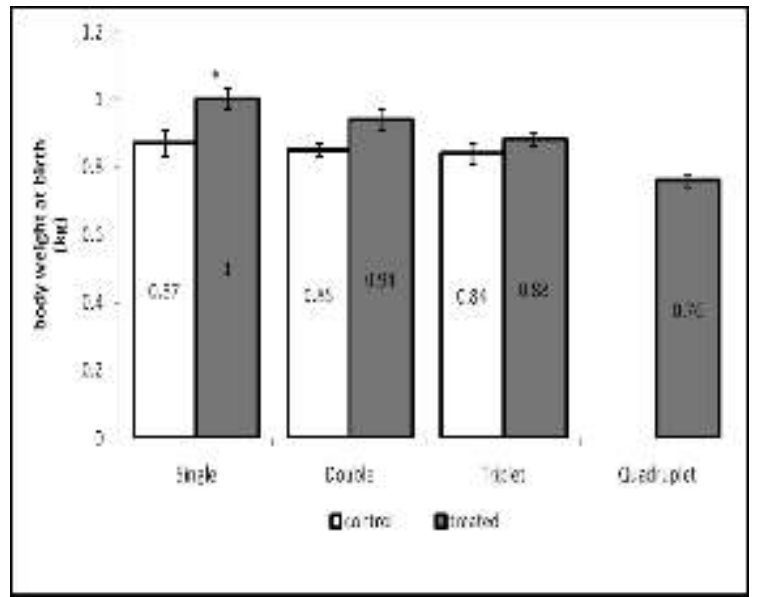

Figure 3. Mean litter weight born from single, double, triplet and quadruplet births of control and treated group of does.

$0.85 \pm 0.02 \mathrm{~kg}(\mathrm{n}=15)$ and $0.84 \pm 0.03 \mathrm{~kg}(\mathrm{n}=7)$ respectively the difference being non-significant. However, in treated group the difference in mean litter weight born was significant $(\mathrm{P}<0.05)$ for single $(1 \pm$ $0.03 ; \mathrm{n}=4)$, double $(0.94 \pm 0.03 ; \mathrm{n}=9)$, triplet $(0.88 \pm$ $0.02)$ and quadruplets $(0.76 \pm 0.02)$.

\section{Discussion}

Shortening of estrous length by early progesterone exposure has also been observed in ewes (Woody et al., 1967) and cows (Ginther, 1970). Progesterone receptors are down-regulated by progesterone after a period of continuous exposure (Wathes, 1996). Moreover, progesterone down-regulates endometrial oxytocin receptors (Dunlap, 2004). Therefore the shortening of estrous length by progesterone was due to early luteolysis caused by early up-regulation of endometrial oxytocin receptors.

Another possible reason for the premature luteolysis is an inadequate luteotrophic support after ovulation, when LH pulses are essential for CL development. This might be the underlying phenomenon behind shorter estrous length observed in does (group 4) treated with larger dose of progesterone. Menchaca and Rubianes (2001) observed that Saanen/Anglo Nubian cross bred goats exposed to progesterone early had short (around 8 days) and shortened cycles (around 18 days). However none of the does treated with $10 \mathrm{mg}$ and $30 \mathrm{mg}$ progesterone in our experiments had short (8 days) estrous cycle.

In ruminants interferon tau secreted by the conceptus is the major signal for maternal recognition of pregnancy (Robert et al., 1999) that abrogates 
luteolysis by down-regulation of endometrial oxytocin and estradiol receptors (Spencer and Bazer, 1996). Premature luteolysis as observed in early progesterone treated non-mated group was not observed in mated group (group $5 \& 6$ ), probably due to early secretion of interferon tau by the conceptus as has been observed in cows (Mann et al., 2006). Early appearance of embryonic vescicles in early progesterone treated groups clearly suggests that early progesterone exposure stimulates the growth and maturation of the embryo resulting to early release of interferon tau.

Estradiol and oxytocin treatment on day 8 and day 9 to groups 7 and 9 brought the does to heat on day 12. Such an effect was due to luteolysis caused by upregulation of endometrial oxytocin receptors by estradiol (Beard and Lamming 1994) and subsequent release of $\mathrm{PGF}_{2 \alpha}$ by oxytocin (Fairclough et al., 1980). Early progesterone exposure hastened conceptus growth and maturation as has already been discussed thereby abrogating the luteolytic effect of estradiol and oxytocin (Spencer and Bazer, 1996) as observed in $30 \mathrm{mg}$ progesterone treated group (group 8). However, this effect was not observed in $10 \mathrm{mg}$ progesterone treated group (group 7) probably due to the fact that development and growth of embryo was not optimum to release adequate amount of interferon tau to abrogate luteolysis.

At low dose estradiol does not have any adverse effect on conceptus growth and survival (Vallet and Cristenson, 2004) if administered after implantation of conceptus has been accomplished. Premature parturitions have been attempted in goats by administration of estradiol at high dose (4-8 mg; Currie et al., 1976) and this was mediated by uterine $\mathrm{PGF}_{2 \alpha}$. However, our dose of estradiol was much lower to warrant such an effect. Moreover, progesterone and oxytocin have positive effect on folliculogenesis and ovulation (Roshnagar et al., 2009; McLeod and Heresign, 1984), thus the does those failed to conceive returned to heat promptly. Therefore early progesterone treatment not only stimulates conceptus growth and maturation but also shortens the length of estrous cycle, estradiol and oxytocin further aiding in bringing the does to heat and timely ovulation.

The results of experiment 2 indicate that early progesterone treatment not only improved the conception rate but also increased the percent of twin, triplet and quadruplet births. Progesterone treatment early during the estrous cycle has been found to hasten the growth and maturation of conceptus (Mann et al., 2006) thereby resulting in greater survivality. Early and greater release of interferon tau by the conceptus exposed to early progesterone abrogates early luteolysis caused by premature release of uterine $\mathrm{PGF}_{2 \alpha}$ or delayed secretion of interferon by the conceptus (i.e. asynchrony in MRP). Thus greater conception rate and percentage of twins, triplets and quadruplets observed in progesterone treated group was due lower early embryonic death.

For single birth the mean litter weight at birth was significantly better for early progesterone treated group than control. There was significant reduction in birth weights for single, double and triplet births in progesterone treated groups. Hussain et al., (1997) found significant difference in mean birth weight of Black Bengal kids for single, double and triplet kidding.

\section{Conclusion}

We conclude that early pregnancy diagnosis can be successfully done by early progesterone and estradiol treatment. Estradiol treatment at the dose rate of $500 \mu \mathrm{g}$ during the diestrous in does results in premature luteolysis and animals returning to heat, provided the uterus is pre-exposed to progesterone. Progesterone + estradiol combination results in shortened estrous (12 days approximately) if the does fail to conceive. Such treatment reduces early embryonic losses thereby improving the conception rate without compromising on mean litter weight born.

\section{Acknowledgements}

We acknowledge Department of Veterinary Physiology, West Bengal University of Animal \& Fishery Sciences, Belgachia, Kolkata-37 for the great help in providing us the ultrasonography machine (Mindray, Senzhen, China). This work has been performed by the authors of their own interest and the animals used in this study were chosen from villages with the consent of the farmers.

\section{Conflict of interest}

Authors declare that they have no conflict of interest.

\section{References}

1. Beard, A. P. and Lamming, G. E. (1994) Estradiol concentration and the development of uterine oxytocin receptors and oxytocin induced $\mathrm{PGF}_{2} \alpha$ release in ewes. J. Reprod. Fertil. 100: 469-475.

2. Currie, W. B., Cox, R. L. and Thorburn, G. D.(1976). Release of prostaglandin F, regression of corpora lutea and induction of premature parturition in goats treated with estradiol-17ß. Prostaglandins. 12(6): 1093- 
1102.

3. Dunlap K A. and Stromshak F.(2004). Nongenomic inhibition of oxytocin binding by progesterone in the ovine uterus. Biol. Reprod. 70: 65-69.

4. Fairclough, R.J., Moore, L.G., McGowan, L.T., Peterson, A.J., Smith, J.F., Tervit, H.R., Watkins, W.B., (1980). Temporal relationship between plasma concentrations of 13-14-dihydro-15-keto- $\mathrm{PGF}_{2} \alpha$ and neurophysin I/II around luteolysis in sheep. Prostaglandins. 20: 199-208.

5. Ginther, O. J. (1970). Effect of progesterone on length of estrous cycle in cattle. Am. J. Vet. Res. 31:493-496.

6. Hussain, S. S., Horst, P. and Islam, A. B. M. M. (1997). Growth performance of Black Bengal goats in different regions of Bangladesh. AJAS 10(5): 491494.

7. Mann G E, Fray M D and Lamming G E. (2006). Effects of time of progesterone supplementation on embryo development and interferon-tau production in the cow. Vet. J. 171(3): 500-503.

8. McLeod, B. J. and Haresign, W. (1984) Evidence that progesterone may influence subsequent luteal function in the ewe by modulating preovulatory follicle development. J. Reprod. Fert. 71:381-386.

9. Menchaca, A and Rubianes, E. (2001). Effect of high progesterone concentrations during the early luteal phase on the length of the ovulatory cycle of goats. Anim. Reprod. Sci. 68: 69-76.

10. Roberts R M, Ealy A D, Alexenko A P, Han C S and Ezashi T. (1999). Trophoblast interferons. Placenta 20: 259-264.

11. Roshnagar, L., Rad. J. S., Nikpoo, P., Melli, M.S. (2009). Effect of oxytocin injection on olliculogensis, ovulation and endometrial growth in mice. IJRM. 7(2): 91-95.

12. Spencer, T. E. and Bazer, F. W. (1996). Ovine interferon tau suppresses transcription of estrogen receptor and oxytocin receptor genes in the ovine endometrium. Endocrinol. 137: 1144-1147.

13. Vallet, J. L. and Christenson, R. K. (2004) Effect of progesterone, mifepristone, and estrogen treatment during early pregnancy on conceptus development and uterine capacity in swine. Biol. Reprod. 70: 92-98.

14. Wathes D C, Mann G E, Payne J H, Riley P R, Stevenson K R and Lamming G E. (1996) Regulation of oxytocin, oestradiol and progesterone receptor concentrations in different uterine regions by oestradiol, progesterone and oxytocin in ovariectomized ewes. $J$ Endocrinol 151: 375-393.

15. Woody, C. O., First, N. L. and Pope, A. L. (1967) Effects of exogenous progesterone on estrous cycle length. J. Anim. Sci. 26: 139-141. 